\title{
Nutrition Phytochemicals Affecting Platelet Signaling and Responsiveness: Implications for Thrombosis and Hemostasis
}

\author{
Funda Tamer ${ }^{1,2}$ Bibian M. E. Tullemans ${ }^{1}$ Marijke J. E. Kuijpers ${ }^{1,30}$ Theodora A.M. Claushuis ${ }^{4, *}$ \\ Johan W. M. Heemskerk ${ }^{1,5, *(1)}$
}

${ }^{1}$ Department of Biochemistry, Cardiovascular Research Institute Maastricht, Maastricht University, Maastricht, The Netherlands

2 Department of Nutrition and Dietetics, Faculty of Health Sciences, Hacettepe University, Ankara, Turkey

${ }^{3}$ Thrombosis Expertise Centre, Heart and Vascular Centre, Maastricht Address for correspondence Marijke Kuijpers, PhD, Department of Biochemistry, Maastricht University, P.O. Box 616, 6200 MD Maastricht, The Netherlands

University Medical Centre, Maastricht, The Netherlands

${ }^{4}$ Department of Internal Medicine, Catharina Hospital, Eindhoven, The Netherlands

${ }^{5}$ Synapse Research Institute Maastricht, Maastricht, The Netherlands (e-mail: marijke.kuijpers@maastrichtuniversity.nl).

Thromb Haemost 2022;122:879-894.

\begin{abstract}
Keywords

- hemostasis

- nutrition

- platelet

- signaling

- thrombosis

Cardiovascular disease, in particular due to arterial thrombosis, is a leading cause of mortality and morbidity, with crucial roles of platelets in thrombus formation. For multiple plant-derived phytochemicals found in common dietary components, claims have been made regarding cardiovascular health and antiplatelet activities. Here we present a systematic overview of the published effects of common phytochemicals, applied in vitro or in nutritional intervention studies, on agonist-induced platelet activation properties and platelet signaling pathways. Comparing the phytochemical effects per structural class, we included general phenols: curcuminoids (e.g., curcumin), lignans (honokiol, silybin), phenolic acids (caffeic and chlorogenic acid), derivatives of these (shikimic acid), and stilbenoids (isorhapontigenin, resveratrol). Furthermore, we evaluated the flavonoid polyphenols, including anthocyanidins (delphinidin, malvidin), flavan-3-ols (catechins), flavanones (hesperidin), flavones (apigenin, nobiletin), flavonols (kaempferol, myricetin, quercetin), and isoflavones (daidzein, genistein); and terpenoids including carotenes and limonene; and finally miscellaneous compounds like betalains, indoles, organosulfides (diallyl trisulfide), and phytosterols. We furthermore discuss the implications for selected phytochemicals to interfere in thrombosis and hemostasis, indicating their possible clinical relevance. Lastly, we provide guidance on which compounds are of interest for further plateletrelated research.
\end{abstract}

\footnotetext{
* Equal contribution.
}

received

June 4, 2021

accepted after revision

October 27, 2021

published online

October 29, 2021 (c) 2021. Thieme. All rights reserved. Georg Thieme Verlag KG,

Rüdigerstraße 14,

70469 Stuttgart, Germany
DOI https://doi.org/

10.1055/a-1683-5599.

ISSN 0340-6245. 


\section{Introduction}

With increasing prevalence around the world, cardiovascular diseases (CVDs) are leading causes of mortality and morbidity, ${ }^{1}$ in which platelets play a crucial role. ${ }^{2}$ In arterial thrombosis and thrombus formation, platelets become activated by several vascular and blood-borne agonists, but with major roles of subendothelial collagens, by secretion of autocoids such as thromboxane $\mathrm{A}_{2}\left(\mathrm{TXA}_{2}\right)$ and ADP, and by the coagulation product thrombin. ${ }^{3,4}$ The conventional concept is that, after rupture of an atherosclerotic lesion, these agonists promote the formation of a platelet aggregate or thrombus, which is consolidated by fibrin clot formation and erythrocyte inclusion leading to vascular occlusion. ${ }^{5} \mathrm{~A}$ similar set of platelet agonists induces in hemostasis the formation of a platelet plug after vascular injury.

Platelets in the circulation are prevented from activation by multiple inhibiting molecules such as prostacyclin, nitric oxide (NO), and antithrombin. ${ }^{2}$ It is understood now that the continuous presence of inhibiting and activating factors establishes a certain balanced state, where platelets are more negatively or positively primed toward activation. ${ }^{6}$ Antiplatelet therapies provide a strong inhibitory effect, and thereby reduce the risk of developing thrombotic complications, however at the expense of bleeding. ${ }^{2,7}$ In the context of cardiovascular health, for long it has been cleared that many nutritional components and metabolites of these can influence the CVD risk. ${ }^{8}$ This also holds for nutrients influencing platelet activation and hence the platelet priming state. In particular, edible plant-derived compounds or phytochemicals have been researched for effects on platelets, often by in vitro studies and less often in nutritional intervention studies. Effects of phytochemicals have been described not only on collagen, thrombin, ADP, or $\mathrm{TXA}_{2}$ receptor-dependent activation processes, but also on specific signaling pathways in platelets. In this review we provide an overview of how the most commonly studied dietary phytochemicals can alter platelet activation properties and platelet signaling pathways.

\section{Phytochemical Classes in Relation to Cardiovascular Health}

Natural products and their synthetic analogues have been used for many decades as drugs for treatment of CVDs. For instance, a substantial part of the small molecules approved for cancer chemotherapy in Western medicine is structurally unmodified or modified natural products. Phytochemicals are plant-derived chemical compounds, produced for biological defense or growth regulation. ${ }^{9}$ From a nutritional or subclinical perspective, the term phytochemical is mostly used for compounds from edible plant parts with a supposed effect on the human physiology, but also some poisons and herbs of traditional medicine can be considered as phytochemicals. In the present article, we focus on nutritional phytochemicals, such as those present in nontoxic plants.

For long, it has been considered that the regular intake of certain phytochemicals can ameliorate physiological pro- cesses by a presumed anti-oxidant, -inflammatory, -estrogenic, -immune, carcinogenic, or cardioprotective action, although for many compounds the evidence for this is still limited or mixed. ${ }^{10}$ For instance, for carotenoids and polyphenols, authorities still discourage the use of specific health or disease claims. ${ }^{11,12}$ In general terms, it can be stated that phytochemicals from common edible plants have relatively small effect sizes on health and disease, given their abundant presence in nutrition, which implies that high amounts may need to be ingested for improving health. At the other side of the spectrum, phytotoxins from nonedible plants often influence physiologic reactions already at low doses with high effect sizes. ${ }^{9,13}$ From the perspective of cardiovascular health, plant-derived compounds that are not abundantly present in the diet with medium effect sizes are most interesting.

The common classification of nutritional phytochemicals is based on their chemical structure rather than on the reactive groups or the in-human metabolization. For the present purpose, four relevant classes are distinguished (-Table 1): general simple phenols (class I), flavonoid polyphenols (II), terpenoids (III), and a miscellaneous set of other compounds (IV).

General simple polyphenols (class I) include over 8,000 identified compounds, occurring in a wide variety of foods. ${ }^{14}$ Structurally, these contain one or more phenol units, several hydroxyl groups, and sometimes a sugar residue (glycoside) attached to a hydroxyl group. ${ }^{15}$ Class subdivision is according to the number and structure of the phenol rings, and to other structural elements. ${ }^{16}$ For examples, see - Supplementary Fig. $\mathbf{5 1}$ (available in the online version). Curcuminoids include the yellow pigment curcumin found in turmeric and ginger species, with several claimed biological effects. ${ }^{17}$ Lignans consist of two phenylpropane units, mostly present as glycosides, and are concentrated in flaxseed (matairesinol), rye (pinoresinol), magnolia bark (honokiol), and some seeds (silibinin). In vitro studies point to antioxidant and anticarcinogenic activities. ${ }^{18,19}$ The simple phenolic acids contain a hydroxybenzoic or hydroxycinnamic acid group. The former set includes gallic acid that is relatively rare in grapes, teas, and legume seeds. ${ }^{20}$ Compounds of the latter set are seen in many foods. Examples are caffeic and its ester chlorogenic acid, present in coffee beans and fruits, with health claims in the oncologic and cardiovascular areas. ${ }^{21,22}$ Structurally, salicylic acid (aspirin) from nonedible willow leaves is also a phenolic acid. The phenolic acid derivative ellagic acid is a natural antioxidant found in numerous fruits and vegetables. Stilbenoids are derivatives of the bi-phenol stilbene. Best known is the stilbenoid resveratrol, found in grapes, peanuts, and red wine. Studies propose anticancer or antiatherogenic effects. ${ }^{23,24}$

Flavonoid polyphenols (class II) form the majority of phenolic compounds in vegetables, fruits, nuts, beverages, and medicinal herbs. ${ }^{25}$ These water-soluble flavonoids contain two aromatic rings with one or more hydroxyl groups and 15 carbon atoms (-Supplementary Fig. S1, available in the online version), and are subclassified into six groups ( - Table 1). A large database of the flavonoid content of foods 
Table 1 Structural-based classification of phytochemicals linked to thrombosis and hemostasis, typical examples and presence in food components

\begin{tabular}{|c|c|c|}
\hline Class phytochemical & Examples & Enriched in food components \\
\hline \multicolumn{3}{|l|}{ I. General phenols $(>8,000)$} \\
\hline a. Curcuminoids & Curcumin, demethoxycurcumin & Ginger, turmeric \\
\hline b. Lignans & Honokiol, pinoresinol, silibinin, silybin & Bark, cereals, flax seed, thistle seed, rye \\
\hline c. Phenolic acids & $\begin{array}{l}\text { Caffeic, chlorogenic, coumaric, gallic, } \\
\text { salicylic acids }\end{array}$ & Coffee bean, fruits, grains, vegetables \\
\hline d. Phenolic acid derivatives & Ellagic, shikimic acids & Nuts, oak \\
\hline e. Stilbenoids & Isorhapontigenin, resveratrol, piceatannol & Berries, grape, peanut, red wine \\
\hline \multicolumn{3}{|c|}{ II. Flavonoid polyphenols $(>5,000)$} \\
\hline a. Anthocyanidins & $\begin{array}{l}\text { Anthocyanin, cyanidin, delphinidin, malvidin } \\
\text { (glycosides) }\end{array}$ & Dark colored berries, fruits, vegetables \\
\hline b. Flavan-3-ols & $\begin{array}{l}\text { Catechin, epicatechin, gallocatechin, } \\
\text { theaflavin }\end{array}$ & Cocoa, fruits, legume seeds, black teas \\
\hline c. Flavanones & $\begin{array}{l}\text { Eriodictyol, hesperetin, hesperidin, } \\
\text { naringenin (glycosides) }\end{array}$ & Grapefruit, lemon, orange, tomato \\
\hline d. Flavones & Apigenin, luteolin, morin, nobiletin & Carrot, celery, citrus, pepper, spices, spinach \\
\hline e. Flavonols & $\begin{array}{l}\text { Fisetin, galangin, kaempferol, myricetin, } \\
\text { quercetin }\end{array}$ & $\begin{array}{l}\text { Broccoli, berries, green teas, fruits, nuts, } \\
\text { union }\end{array}$ \\
\hline f. Isoflavones & Daidzein, equol, genistein, glistein & Legumes, soybean \\
\hline \multicolumn{3}{|l|}{ III. Terpenoids $(>4,000)$} \\
\hline $\begin{array}{l}\text { a. Carotenoids } \\
\text { (tetraterpenoids) }\end{array}$ & Carotenes, lutein, lycopene, zeaxanthin & Carrot, corn, tomato, paprika \\
\hline b. Monoterpenes & $\begin{array}{l}\text { Carvone, limonene, menthol, pinene, } \\
\text { sabinene }\end{array}$ & Barks, citrus oil, mint, pepper \\
\hline $\begin{array}{l}\text { c. Sesquiterpenes } \\
\text { (-penoids) }\end{array}$ & Abscisic acid, humulone, zingiberene & Hop, ginger \\
\hline \multicolumn{3}{|l|}{ IV. Miscellaneous } \\
\hline a. Betacyanins & Isobetanin, betanin, neobetanin & Beet, food dyes, fruits \\
\hline b. Betaxanthins & Indicaxanthin, portulaxanthin & Beet, cactus \\
\hline c. Indoles & Indole-3-carbinol & Broccoli, cabbage \\
\hline d. Organosulfides & Allicin, diallyl disulfide, and trisulfide & Garlic, leek, union \\
\hline e. Phytosterols & $\beta$-Sitosterol, campesterol, stigmastanol & Coconut, corn, olive, palm, sunflower oils \\
\hline
\end{tabular}

Note: Grouping is based on the plant component review of Frank et al. ${ }^{126}$ For references, see the text.

was already established in 2003 by the United States Department of Agriculture, and by today contains over 5,000 molecules.

Anthocyanidins (flavonoid polyphenols) are abundantly present in the epidermal cells of berries, flowers, and fruits, and give these plant parts their pink to purple colors. ${ }^{14}$ Partly accepted health claims are protection against obesity or diabetes, due to antioxidant, anti-inflammatory, or hypolipidemic actions. ${ }^{26}$ Delphinidin (in violets) and malvidin (in primroses and grapes) are examples of anthocyanidins; the corresponding glycosides are called anthocyanins. Flavan-3ols such as epicatechin are catalogued as derivatives with a phenyl chromenol skeleton (-Supplementary Fig. S1, available in the online version). They include catechin-like compounds and theaflavin, which are found in cacao, fruits, legume seeds, and teas. A health claim benefit of catechins in tea and wine has been disapproved, but a similar claim of (high-caloric) dark chocolate for ameliorating blood flow is still on the table. ${ }^{27}$ Flavanones with a ketone group have a reactive structure (- Supplementary Fig. S1, available in the online version), and are sensitive to hydroxylation, glycosylation, and O-methylation. Orange-like fruits and tomato are some of the edible sources. Present as glycosides are eriodictyol in lemon, hesperidin in orange, and naringenin in grapefruit. ${ }^{14}$ Such citrus flavanones have been studied for supposed antioxidant and lipid-lowering effects. ${ }^{28}$ Flavones with a phenylchromenone backbone are also found as glycosides in spices and in yellow/orange fruits and vegetables. ${ }^{14}$ Well-known flavones are apigenin, nobiletin, and luteolin, with antioxidant or anti-inflammatory activities. ${ }^{29}$

Flavonols with a hydroxy-phenylchromenone backbone form the most common flavonoid polyphenols of some foods. 
Flavonols include the compounds fisetin, kaempferol, myricetin, and quercetin. ${ }^{30}$ They are enriched in broccoli, berries, fruits, leek, and onion, cumulating as a daily intake of 20 to $50 \mathrm{mg} .{ }^{14} \mathrm{~A}$ meta-analysis suggested that flavonols may help in decreasing CVD risk factors. ${ }^{31}$ Isoflavones comprise flavonoids with a structural similarity to estrogens, although they are not steroids, and hence may have pseudo-hormonal properties. Isoflavones like daidzein, equol, and genistein are found in legumes and soybean, available with or without glycoside residues. ${ }^{14}$ An earlier review discussed how isoflavones can act health-enhancing in obesity. ${ }^{32}$

The third class of terpenoids (III) represents a large family with over 4,000 primary and secondary plant metabolites (-Table 1). The terpenoids have an isoprene unit in common, and are subdivided according to the number of carbon atoms. Carotenoids (tetraterpenoids) are fat-soluble yellow-red pigments, of which 50 members are present in the common diet ( $\alpha$ and $\beta$ carotene, lycopene, zeaxanthin). Their antioxidant properties are often studied, as well as the role of carotenes as precursors of vitamin A biosynthesis. ${ }^{33}$ The cyclic monoterpene limonene is a major component of citrus peel oil. It is also in use as a lipophilic solvent for cleaning purposes. Sequiterpenes with three isoprene units are found in essential oils and are infrequently studied with regard to health.

For the purpose of this review, remaining miscellaneous compounds are combined as class IV phytochemicals (-Table 1). Betalains like betanin and the related $\beta$-xanthins comprise yellow to red tyrosine-derived pigments, found in beets and cactuses, and are also popular as natural food dyes. Indoles (after the parent indole group, - Supplementary Fig. S1, available in the online version), in particular indole-3-carbinol (in cabbage), have been studied for supposed anticancer properties. ${ }^{34}$ Organosulfides, abundant in Allium plants such as garlic, onion, and leek, include the sulfurcontaining allicin and diallyl sulfides. ${ }^{35}$ A Cochrane review concluded insufficient evidence for health claims of garlic as having antithrombotic, hypoglycemic, or lipid-lowering activity. ${ }^{36}$ Phytosterols, i.e., plant sterols and stanols, with a structural resemblance to cholesterol, are present in many vegetable oils, and have a discussable health claim for beneficial lipid-lowering effect. Some international societies still advise phytosterols as an additional dietary option in the management of hypercholesterolemia; however, other guidelines such as those from the National Institute of Health are more critical and draw attention to significant safety issues. ${ }^{37}$ In general, in some parts of the world a high burden of proof is required for supplements or phytochemicals for health claims to be made, even meaning that clinical trials are required.

\section{Platelet Signaling Pathways Targeted by Phytochemicals}

Published studies to effects of certain classes of phytochemicals on platelets mostly describe altered responses such as $\mathrm{TXA}_{2}$ release, platelet aggregation, or granule secretion, induced by agonists interacting with key platelet receptors. - Fig. 1 provides a simplified scheme, for relating these responses to specific signaling pathways, based on previous reports. ${ }^{3-5}$ In brief, $G$-protein coupled receptors for $\mathrm{ADP}, \mathrm{TXA}_{2}$, and thrombin activate platelets via phospholipase $C \beta$ and protein kinase $C$ (PKC) isoforms, whereas especially the P2Y $Y_{12}$ ADP receptor triggers integrin $\alpha_{I I} \beta_{3}$ activation via the route of phosphoinositide 3-kinases (PI3K), protein kinase $\mathrm{B}$ (PKB or Akt), and glycogen synthase kinase (GSK). Elevated cytosolic $\mathrm{Ca}^{2+}$ is required for the cyclooxygenasedependent production of $\mathrm{TXA}_{2}$, in a manner enforced by isoforms of mitogen-activated protein kinases (MAPKs) such as ERK and p38. Another route to platelet activation is provided by tyrosine-kinase-linked receptors, in particular the glycoprotein VI (GPVI) receptor for collagen. Here, via the kinases Src and Syk, platelet activation is achieved via PLCr and PKC isoforms, both required for granule secretion. Under physiological conditions, platelet inhibition is accomplished by the CAMP- and cGMP-dependent protein kinases PKA and PKG, which become active via endothelial-derived prostaglandin $\mathrm{I}_{2}\left(\mathrm{PGI}_{2}\right.$, IP receptor) and $\mathrm{NO}$, respectively. Isoforms of cAMP- and cGMP-dependent phosphodiesterases (PDEs) counteract this inhibition. In comparison to nucleated cells with proliferative, immune, and inflammatory actions, the roles of some signaling pathways in platelets are less well clarified. This concerns the signaling entities JAK (Janus kinase), mTOR (mechanistic target of rapamycin), or NFKB (nuclear factor kappa-enhancer of activated B cells).

\section{Searching for Relations between Phytochemicals and Signaling Pathways}

As a systematic approach to link common phytochemicals to signal transduction pathways relevant for platelets, we performed a set of PubMed searches (April 3, 2021). This search included papers in which phytochemicals were mentioned in combination with each of the 19 signaling modules mentioned above, regardless of the cell type. We then filtered for papers also mentioning "platelet." The complete datasets with phytochemicals arranged per class are given in Supplementary Datafile 1 (available in the online version). A histogram of the total number of papers (integrating all signaling pathways) indicated that the most prominently investigated compounds are $(\geq 1,500$ counts, phytochemical class in brackets): carotenes (IIIa), genistein (IIf), curcumin (Ia), resveratrol (Ie), quercetin (IIb), catechin (IIb), gallic acid (Ic), and caffeic acid (Ic) (-Fig. 2A). To some extent, this also holds for the counts including platelets, with a notable exception that the most commonly mentioned phytochemical is genistein (215 counts), followed by quercetin (108 counts) (-Fig. 2B).

Examining the distribution profiles of these counts among the 19 selected signaling entities (PLC, PKC, PI3K, Akt, GSK, MAPK, ERK, p38, PDI, NO, cGMP, cAMP, PDE, Src, SHP, JAK, NFKB, mTOR, COX) revealed some interesting patterns. A condensed heatmap for all cell types is presented in - Fig. $\mathbf{3 A}$, and with filter for "platelet" in -Fig. 3B (full data in Supplementary Datafile 1, available in the online version). In agreement with the considered broad influence of many phytochemicals on physiological and cellular processes, for 


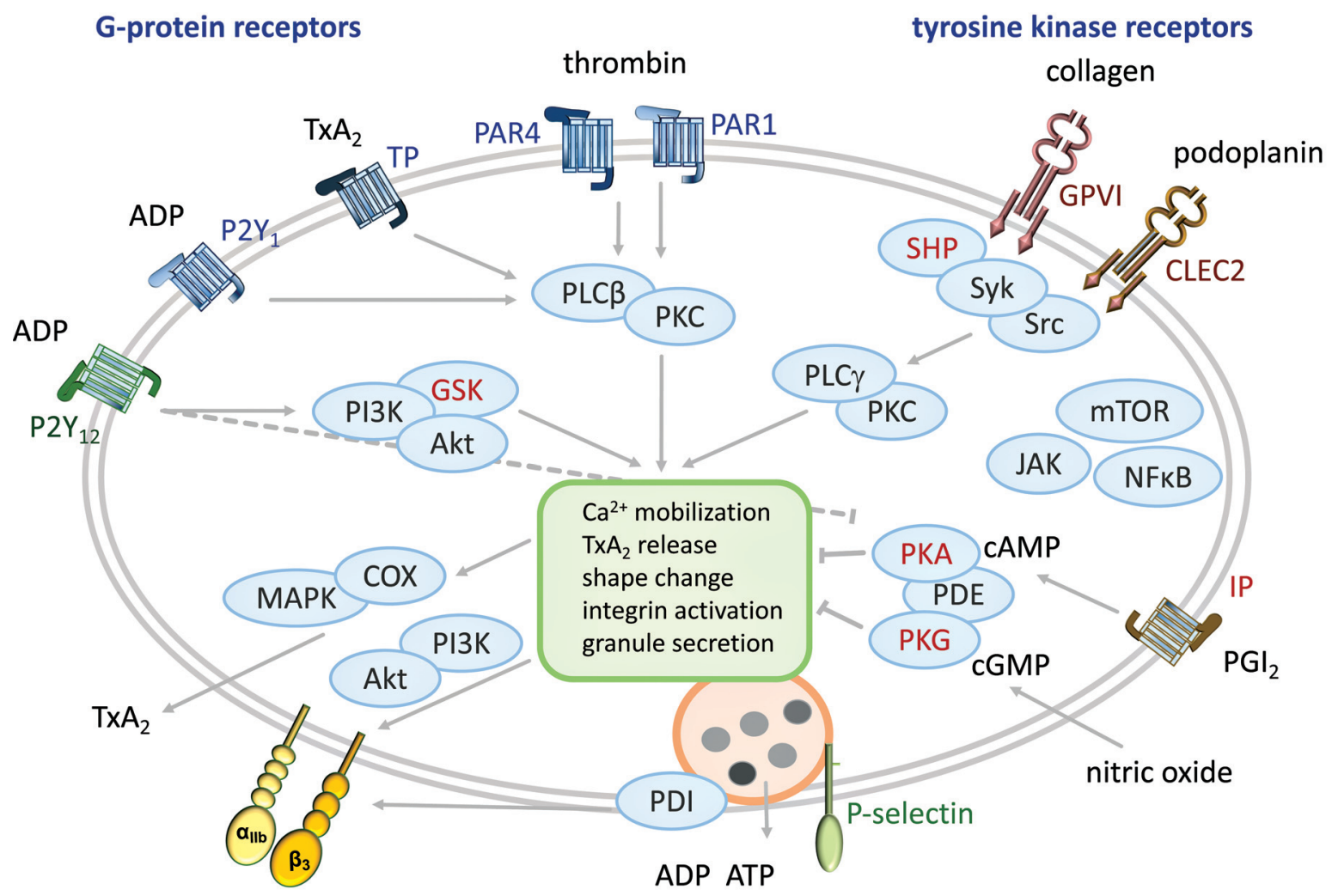

platelet aggregation

platelet inhibition

Fig. 1 General overview of signal transduction pathways underlying platelet activation and platelet inhibition. Triggering of G-protein-coupled receptors and tyrosine-kinase-linked receptors evokes a range of platelet responses, including $\mathrm{Ca}^{2+}$ mobilization, ${ }^{2 X A_{2}}$ release, secretion of autocrine compounds from storage granules, integrin $\alpha_{1 \mathrm{~b}} \beta_{3}$ activation, and platelet aggregation. Note that signaling pathways indicated in red are negative regulators of platelet activation. For further explanation, see the text. COX, thromboxane synthase-cyclooxygenase; GPVI, glycoprotein VI; GSK, glycogen synthase kinase; JAK, Janus kinase; MAPK, mitogen-activated protein kinase; mTOR, mechanistic target of rapamycin; NFKB, nuclear factor kappa-enhancer of activated B cells; PAR, protease-activated receptor; PDE, cyclic nucleotide-dependent phosphodiesterase; PDI, protein disulfide isomerase; $\mathrm{PGI}_{2}$, prostaglandin $\mathrm{I}_{2}$; PI3K, phosphoinositide 3-kinase; PKA, cAMP-dependent protein kinase; PKB, protein kinase B or Akt; PKC, protein kinase C; PKG, CGMP-dependent protein kinase; PLC, phospholipase C; SHP, Src homology region 2 domain-containing phosphatase; Src, cellular tyrosine kinase c-Src.

the general analysis we obtained high counts for quite diverse pathways, i.e., NO (8k) $>$ Akt, NFKB (5k) $>$ MAPK, ERK, p38, COX (3k)> PKC, cAMP (2k) (Supplementary Datafile 1, available in the online version). After filtering for "platelet," the orders changed moderately, i.e., NO, PDE, Akt $(>100)>$ MAPK, p38, cAMP, COX $(>70)>$ PKC, PI3K, Src $(>50)$. Examination of the unfiltered distribution profiles for all cell types indicated that especially curcumin (Ia), resveratrol (Ie), catechin (IIb), quercetin (IIe), genistein (IIf), and carotene (IIIa) showed an abundant and broad spectrum of links to general signaling pathways (-Fig. 3A). This distribution remained similar after filtering for "platelet" (-Fig. 3B). Markedly, for the phytochemicals of classes I-II, average hits ( \pm standard deviation) as percentages were highest for NO $(19 \pm 7 \%)$, followed by NFKB $(14 \pm 4 \%)$ and $\operatorname{COX}(8 \pm 2 \%)$. After filtering for "platelet," these percentages were for NO $(14 \pm 20 \%)$, NFKB ( $3 \pm 5 \%)$, and COX $(10 \pm 19 \%)$. This is in agreement with the relatively poorly defined role of the NFKB pathway in platelets and the well-understood role of the aspirin-sensitive COX pathway in platelets.
In general, phytochemicals of classes III and IV are less frequently examined with regard to signaling pathways, most prominent being carotene (IIIa), lycopene (IIIa), sitosterol (IVe), indole-3-carbinol (IVc), diallyl trisulfide (IVd), and allicin (IVd). For platelets, with the exception of carotene and lycopene, there were only few hits.

\section{Platelet Activation Affected by General Phenols (Class I)}

When comparing the published effects of specific phytochemicals on platelets (-Table 2 ), it becomes apparent that mostly relatively high doses have been used in assays with washed platelets or platelet-rich plasma. A variety of platelet responses have been tested using aggregation measurements (by light transmission aggregometry, platelet function analyzer, or thrombus formation), commonly by focusing on specific platelet agonists, i.e., collagen acting via GPVI receptors, thrombin via PAR1,4 receptors, ADP via especially $\mathrm{P}_{2} \mathrm{Y}_{12}$, and $\mathrm{TXA}_{2}$ (including COX activity). Using flow cytometry or 
A

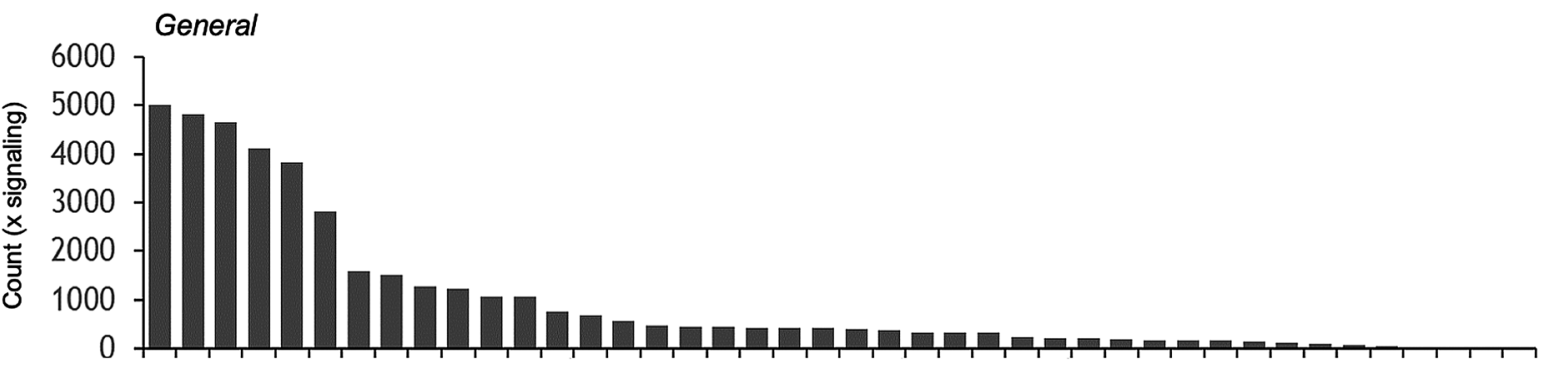

B

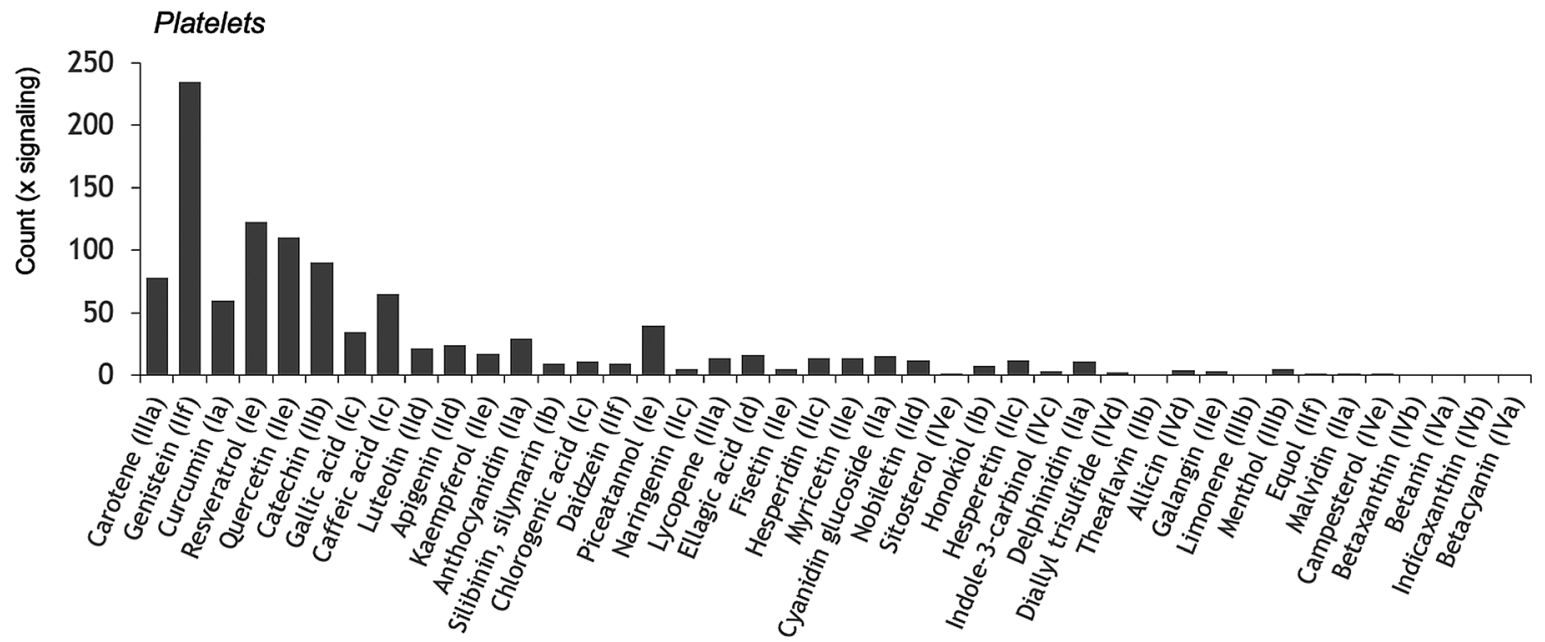

Fig. 2 Publication frequency of common phytochemicals reported in combination with signaling pathways. Summed counts of papers obtained from PubMed (search of April 3, 2021) of commonly studied phytochemicals in combination with 19 signaling entities: PLC, PKC, PI3K, Akt, GSK, MAPK, ERK, p38, PDI, NO, cGMP, cAMP, PDE, Src, SHP, JAK, NFKB, mTOR, and COX. Abbreviations as in - Fig. 1. Shown are the unfiltered general counts (A) and the filtered counts for "platelet" (B). Searches included the title, abstract, and keyword fields. Also shown are the phytochemical classes (roman numbers). Full data are given in Supplementary Datafile 1.

A

General

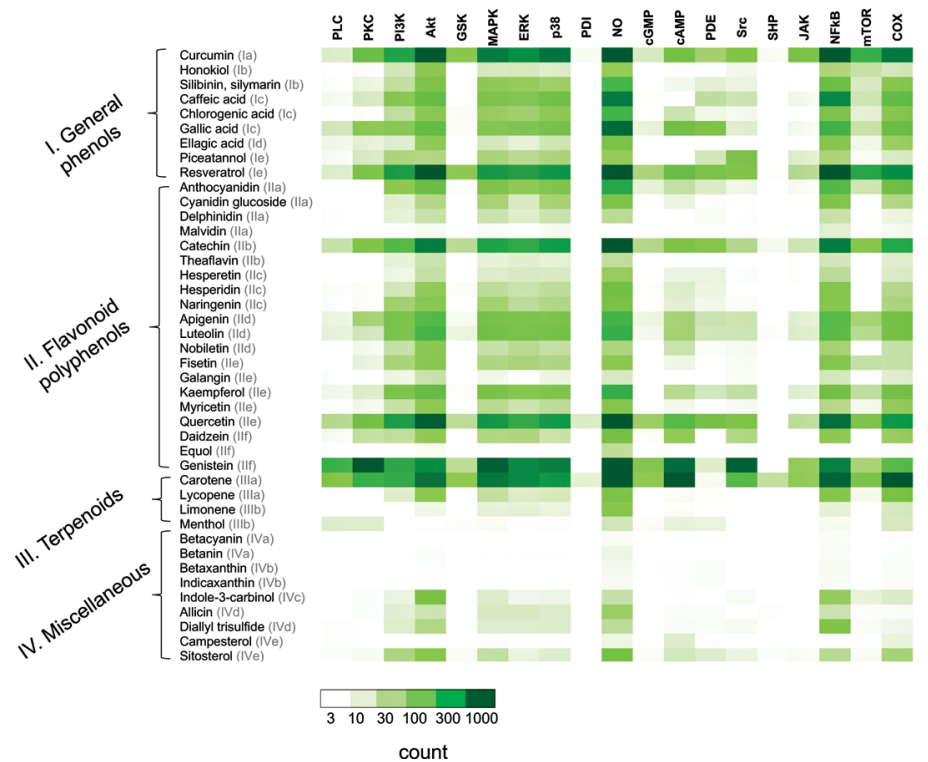

B Platelets

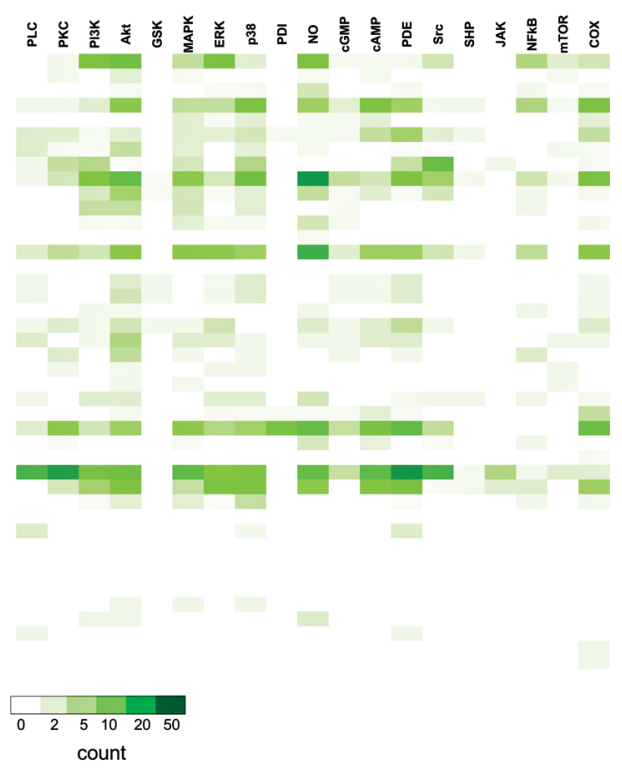

Fig. 3 Distribution of papers reporting on phytochemicals in combination with specific signaling pathways. PubMed search as indicated for - Fig. 2. Shown are the citation distribution of indicated phytochemicals in combination with the signaling entities: PLC, PKC, PI3K, Akt, GSK, MAPK, ERK, p38, PDI, NO, cGMP, cAMP, PDE, Src, SHP, JAK, NFKB, mTOR, and COX. (A) General publications, and (B) after filtering for "platelet." Note that paper inclusion was independent of effect of the phytochemical compounds. Full data are given in Supplementary Datafile $\mathbf{1 .}$ 
luminescence, agonist-induced secretion (with roles of PLC and PKC) and integrin $\alpha_{\mathrm{IIb}} \beta_{3}$ activation (with roles of PI3K and Akt) have been measured. In addition, triggered by the cAMP decrease upon $\mathrm{P}^{2} \mathrm{Y}_{12}$ stimulation, some studies have examined phytochemical effects on (platelet-inhibiting) cAMP elevation or consequent PKA-dependent phosphorylation of the VASP proteins. In spite of the variation in assays, doses, and research approach, trends in phytochemical effects on platelet function can be observed. The total dataset per investigated phytochemical and study is given in Supplementary Datafile 2 (available in the online version), while the summative results are provided in -Table 2 .

Curcumin as the main phenolic curcuminoid of turmeric shows positive results in many drug discovery assays, making it there to a false lead. This may be due to the color of curcumin, which can interfere in many assays. This agrees with our PubMed search, showing high counts with "general interest" pathways of PI3K, Akt, MAPK isoforms, NO, NFKB and $\mathrm{mTOR}$, and COX. Curcumin effects on platelets have been studied up to submillimolar concentrations (- Table 2). Suppressive effects were seen of GPVI-induced aggregation and secretion responses, accompanied by a lower tyrosine phosphorylation of $\mathrm{PLC} \gamma 2 .{ }^{38}$ Suppression of $\mathrm{P}_{2} \mathrm{Y}_{12}$-induced platelet aggregation and integrin activation has been observed as well. Dose studies indicated that also the pathway of (arachidonate-induced) COX activation was sensitive to curcumin, ${ }^{39}$ and that anticoagulant effects exist. ${ }^{17}$ Also in vivo studies revealed that curcumin can protect against collagenepinephrine induced thromboembolism in mice and against $\mathrm{FeCl}_{3}$-induced arterial thrombosis in rats. ${ }^{40}$

Honokiol, a phenolic lignan, has been proposed as a specific inhibitor binding to GPVI, but this was later extended to a broader inhibition of GPVI and other tyrosine kinasedependent pathways. ${ }^{41}$

Silybin, along with silychristin and silydianin, all flavonolignans, has been evaluated mostly by one laboratory for $\mathrm{ADP} / \mathrm{P}_{2} \mathrm{Y}_{12}$-induced platelet activation, secretion, and integrin signaling (i.e., PI3K, Akt). ${ }^{42,43}$ An effective dose of $10^{-5} \mathrm{M}$ was reported, which is a physiologically reasonable concentration. ${ }^{44}$

Several authors have described effects of the polyphenolic caffeic acid (present in coffee beans, spices, red wine, chokeberry) at $10^{-5} \mathrm{M}$ ranges, testing different aspects of platelet activation. The antioxidant activity of caffeic acid ${ }^{45}$ may explain at least parts of its action. In vitro studies using human or mouse platelets claim especially a lowering of thrombin- (PAR1,4) and ADP-induced platelet signaling, including secretion, integrin activation, and aggregation, with possible contributions of the pathways of COX, Akt, and ERK ${ }^{46-48}$ A study with rat platelets points to stimulation of PKA-dependent processes, with collagen resulting in a decreased $\mathrm{Ca}^{2+}$ mobilization and $\mathrm{TXA}_{2}$ formation. ${ }^{49}$ An in vivo mouse study revealed that caffeic acid reduced thrombus formation, paralleling inhibition of ADP-induced platelet responses, with suggested roles of MAPK isoforms and PKA stimulation. ${ }^{50}$

Chlorogenic acid (polyphenolic ester of caffeic and quinic acid), also with antioxidant properties, has been studied in relation to various pathologies. One paper using platelets describes a range of GPVI-, PAR-, and ADP-dependent inhibitory effects (secretion, aggregation, and flow adhesion), with a possible role of adenosine receptor activation in the CAMPPKA pathway. ${ }^{51}$

Gallic acid, a phenolic acid, esterifies with other phytochemicals like catechins to form gallates, ${ }^{52}$ and is easily oxidized. By itself, gallic acid was found to have no more than modest effects on collagen and thrombin receptorinduced platelet responses, with even lower activities in the presence of plasma. ${ }^{53,54}$

The polyphenolic acid derivative shikimic acid at $10^{-3} \mathrm{M}$ moderately affected $\mathrm{P}_{2} \mathrm{Y}_{12}$, but not GPVI-dependent platelet responses. ${ }^{55}$

Stilbenoids that are regularly studied are the analogs isorhapontigenin and resveratrol, both of which are panassay interference compounds, hence linking to a wide variety of signaling pathways. This also holds for platelet research. Isorhapontigenin (in Chinese herbs and grapes) in the $10^{-5} \mathrm{M}$ range was found to inhibit ADP/P2Y 12 -induced platelet aggregation, along with effects on PI3K-Akt (inhibitory) and cAMP-PKA (enhancing) signaling. ${ }^{56}$ The analog resveratrol suppressed both collagen- and thrombin-induced platelet aggregation and secretion, ${ }^{56,57}$ with a possible role of $\operatorname{coX}^{53}$ In washed platelets, but not in whole blood, resveratrol inhibited collagen-induced MAPK activation. ${ }^{58}$

\section{Platelet Activation Affected by Flavonoid Polyphenols (Class II)}

Anthocyanidin-flavonoid compounds commonly studied include mixed preparations, cyanidin-3- and delphinidin-3glucoside ( - Table 2 ). In washed platelets, anthocyanins at $10^{-6} \mathrm{M}$ appeared to suppress PAR1-induced responses. ${ }^{59}$ In whole blood, of the various anthocyanidins tested, only cyanidin-3-glucoside at $10^{-6} \mathrm{M}$ was found to downregulate integrin activation with ADP. ${ }^{60}$ The same compound at $10^{-5}$ $\mathrm{M}$ antagonized GPVI-induced signaling (Syk, Src), along with collagen-dependent thrombus formation under flow ${ }^{61}$ and murine thrombus formation in vivo. ${ }^{61}$ Such doses are close to the bioavailable concentration. ${ }^{62}$ Delphinidin-3-glucoside was similarly effective on thrombus formation in mouse. ${ }^{63}$

Catechins comprise antioxidant flavan-3-ols present in cocoa, teas, fruits, and traditional herbs. In platelets, an antioxidant role has indeed been reported. ${ }^{64}$ Reported inhibitory effects of catechins on collagen-induced platelet responses may not be directly downstream of GPVI, but by interfering with secondary mediators. ${ }^{65}$ Yet, catechins derived from green tea showed inhibitory effects on aggregation via GPVI, PAR, and P2 $\mathrm{Y}_{12}$ aggregation and the connected PLC pathway. ${ }^{66}$ The catechin derivative, epigallocatechin gallate, may inhibit (rat) platelet activation via MAPK (p38), TXA $_{2}$ production, and/or cAMP elevation. ${ }^{52,67}$

Apigenin, a yellow colored flavone, was proposed to inhibit platelets activated through PARs and other agonists by binding to the TXA $A_{2}$ receptors $\left(\mathrm{IC}_{50} \sim 17 \mu \mathrm{M}\right),{ }^{68}$ and/or by interfering with intracellular $\mathrm{Ca}^{2+}$ signaling. ${ }^{69}$ Of other flavones, in one paper morin was found to dampen collagen- 


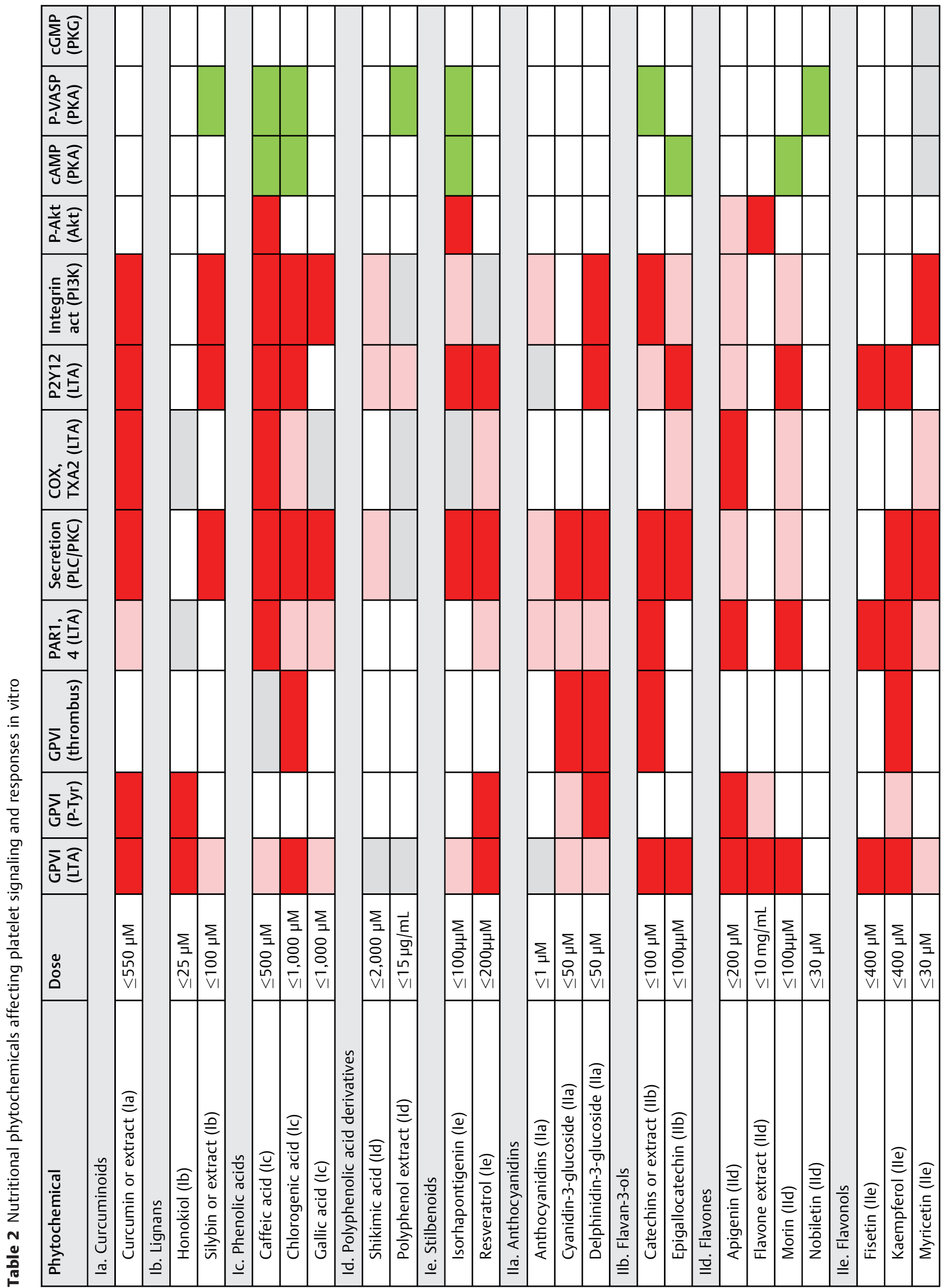




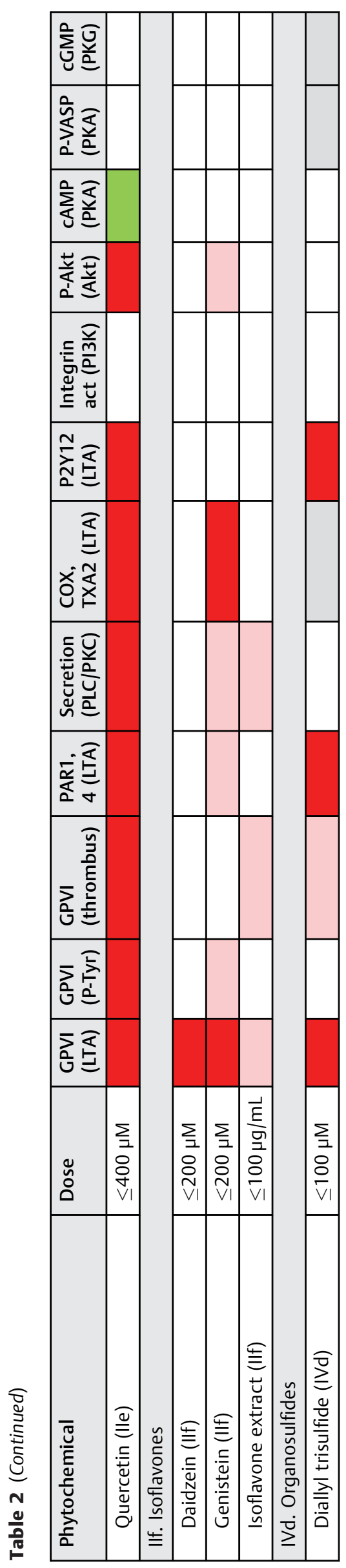

and thrombin-induced platelet responses with suggested roles of the PLC, PI3K, Akt, MAPK (p38, ERK), and cAMP pathways. ${ }^{70}$

The flavonols fisetin and kaempferol $\left(10^{-4} \mathrm{M}\right)$ may have similar inhibiting profiles regarding collagen and thrombin stimulation. Kaempferol was shown to attenuate thrombininduced phosphorylation of PI3K, Akt, ERK, and p38, and suppress murine thrombus formation. ${ }^{71}$

Myricetin exemplifies a flavonol with antioxidant properties, present in a range of vegetables, fruits, nuts, berries, and teas. It can partly reduce GPVI- and PAR-mediated responses, ranging from platelet aggregation, fibrinogen binding, granule secretion, and platelet adhesion under flow. Molecular docking studies pointed to an interaction with PDI, thus providing a mechanism for integrin inhibition and platelet aggregation. ${ }^{72} \mathrm{~A}$ required dose in the $10^{-5} \mathrm{M}$ range was reached in rats after oral intake of $100 \mathrm{mg} / \mathrm{kg} .{ }^{73}$ Relatively high effective doses are needed in the presence of plasma, when compared with washed platelets. ${ }^{72}$ For myricetin also antiplatelet effects via COX have been described. ${ }^{74}$

Quercetin: the flavonol quercetin is a popular candidate antiplatelet phytochemical, acting at relatively low doses $\left(10^{-5} \mathrm{M}\right)$. In agreement with COX being one of the most frequent PubMed hits, quercetin may directly bind to COX. ${ }^{53}$ Another report indicates a reduction of collagen and $\mathrm{TXA}_{2}$ receptor- as well as COX-dependent platelet responses and of underlying signaling reactions. ${ }^{68}$ Several studies point to an inhibitory effect of quercetin and its metabolites on collagen (GPVI)-induced platelet signaling (tyrosine phosphorylation) and aggregation. ${ }^{65,69,75}$ However, quercetin can also suppress thrombin-induced platelet responses by interfering with the signaling $\left(\mathrm{IC}_{50} \sim 40 \mu \mathrm{M}\right) .{ }^{69}$ Early papers reported an effect of quercetin on (controversial) NO release from platelets, ${ }^{76}$ or on inhibition of PDE to stimulate the CAMP-PKA pathway. ${ }^{77,78}$ Synergistic inhibitory effects on collagen-induced platelet aggregation were obtained by quercetin in combination with catechin (both present in grape). ${ }^{64,79}$

Genistein (isoflavone from soy bean with antioxidant properties) has widely been studied for example to activate PPARs (peroxisome proliferator-activated receptors) or inhibit tyrosine kinases, providing it with a complex (anti) carcinogenic potential. Daidzein is a related isoflavone, which is considered to be inactive regarding tyrosine kinases. On platelets, both compounds at $10^{-5} \mathrm{M}$ reduced the aggregation with collagen. ${ }^{80,81}$ Confusingly, genistein was found to block Src phosphorylation, but enhance MAPK activity. ${ }^{82}$ Several papers reported genistein effects on the (PAR-induced) PLC route, ${ }^{68,69,83}$ and TXA $_{2}$-mediated platelet activation. ${ }^{84}$ As a component of soy bean, genistein taken in vivo was thought to suppress collagen-induced platelet aggregation and thrombus formation. ${ }^{81,85}$

\section{Platelet Activation Affected by Other Phytochemicals (Classes III-IV)}

Diallyl trisulfide, an organosulfide present in crushed garlic, has been examined in few platelet papers. As indicated in $\mathbf{-}$ Table 2, studies reported that diallyl trisulfide at $10^{-4}$ to $10^{-5} \mathrm{M}$ decreased (human or animal) platelet aggregation 
induced by collagen, thrombin, or ADP ${ }^{86,87}$ A suggested mechanism was reduced $\mathrm{Ca}^{2+}$ mobilization ( $\mathrm{IC}_{50} \sim 28 \mu \mathrm{M}$ for thrombin and C-reactive protein), but without affecting PLC. ${ }^{88}$ Organosulfides derived from Allium can also modulate platelet sulfhydryl levels, suggesting a modulation of the cytosolic redox state. ${ }^{89}$ Concerning carotenoids, the compound crocin was found to interfere with the formation of reactive oxygen species in platelets by an unknown mechanism. ${ }^{90}$

\section{Nutritional Intervention Studies of Phytochemicals Targeting Platelet Activation}

Multiple controlled intervention studies have been performed with phytochemical-enriched food components, aiming to find antithrombotic effects via platelets (Supplementary Datafile 3, available in the online version). However, the high inter-study heterogeneity in intervention type, duration, and outcome parameters excludes a formal meta-analysis. Across all studies, the overall effect sizes on platelet inhibition appear to be lower after dietary interventions (-Table 3 ) than after in vitro application (-Table 2). Explanations for this are the phytochemical complexity of the food interventions, the relatively low doses ingested, and the fast pharmacokinetics of the plant compounds (rapid metabolic modification and short halflives in the body). ${ }^{14,91}$ As the pharmacokinetics and active metabolites for most phytochemicals are not well established, a direct comparison of in vivo and in vitro studies is not straightforward and can be complex. Another complexity is that studies used different platelet function assays, and that numbers of (healthy) subjects per study usually were low. Yet, it should be noted that these dietary or supplementation intervention studies are major efforts, and that effect sizes are expected to be lower than the effects of approved pharmacological antiplatelet drugs (with a bleeding risk). A summative overview of controlled human intervention studies is given in - Table $\mathbf{3}$, with study details in Supplementary Datafile $\mathbf{3}$ (available in the online version).

General phenols (class I): red wine. Polyphenol-containing red wine consumption has proposed to be thrombo-protective versus white wine consumption. However, several intervention studies did not find evidence for altered platelet activation after moderate consumption of red wine other than an ethanol-related effect. ${ }^{92,93}$ In contrast, in a large placebo-controlled study (72 healthy subjects), 2-week consumption of polyphenol-rich berries appeared to delay collagen/ADP-induced platelet aggregation under shear. ${ }^{94}$

Flavonoid polyphenols (class II): grape seed or kiwi. In a controlled, 8-week study, where flavonoid-containing grape seed extract was given to hypertensive subjects, no evidence for antiplatelet effects was seen. ${ }^{95}$ Regular consumption of kiwi, also containing polyphenols, though led to a reduced collagen/ADP-induced platelet aggregation. ${ }^{96}$

Anthocyanidins (IIa): dark grape juice or anthocyanin supplement. Surprisingly strong antiplatelet effects were reported after regular intake of anthocyanin-rich food additives, in 11 small- to medium-sized controlled studies.
Drinking purple grape juice (but not orange juice) for 1 week reduced collagen-induced platelet aggregation. ${ }^{97}$ In obese subjects, intake of anthocyanin capsules during 4 weeks reduced ADP- and collagen-induced platelet activation parameters. ${ }^{98,99}$ In a large study with 150 hypercholesterolemic individuals, anthocyanin supplementation decreased the plasma levels of platelet secretion products. ${ }^{100}$ In several trials, dark (anthocyanin-rich) plum or orange juice was given to healthy subjects for 1 to 4 weeks (Supplementary Datafile 3, available in the online version). Jointly, these trials identified after intervention a lowering of GPVI- and ADP/P2Y 12 -dependent platelet responses, but not of PAR-dependent responses.

Flavan-3-ols (IIb): dark chocolate or cocoa drink. Supplementation with dark chocolate or cocoa drink, rich in flavan3-ols, mostly by single intake, has also been popular to check for antithrombotic effects (see Supplementary Datafile 3, available in the online version). Overall, the study outcomes indicated a moderate suppression of collagen/GPVI-, thrombin/PAR-, and ADP/P2Y 12 -induced platelet responses (-Table 3). An unexplained gender difference after dark chocolate intake was noted here. ${ }^{101}$ In a large study with 1,535 healthy subjects, again an effect was seen of casual chocolate consumption on collagen- and flow-dependent platelet activation, along with lower $\mathrm{TXA}_{2}$ levels. ${ }^{102}$ Similarly, flavan-3-ol-rich extracts from grapeseed were shown to have a platelet-inhibiting effect under flow in response to collagen/ADP. ${ }^{103}$

Flavonols quercetin and catechin: black tea. Four controlled approximately 4 weeks intervention studies have appeared, where effects were examined of black tea (rich in quercetin and catechins), but no consistent effects on platelet function could be measured (-Table 3 ). One intervention study with 12 subjects reported a strongly decreased collagen/GPVIinduced platelet activation after single intake of quercetin. ${ }^{75}$ However, such quercetin effects were not reproduced in longer time intervention studies. ${ }^{104,105}$

Isoflavones (IIf) genistein and daidzein: soy preparations. An early study examining soy protein (rich in genistein and daidzein) intake during 4 weeks did not find alterations in collagen- or $\mathrm{TXA}_{2}$-induced platelet aggregation. ${ }^{106}$

Organosulfide (IVa) diallyl trisulfide: garlic preparations. Dissimilar from the large effect sizes of diallyl trisulfide on platelet properties in vitro, preparations of this phytochemical in garlic in vivo (given for up to 16 weeks) were no more than weakly active. In small-size studies, reduced effects of intake of garlic preparation on ADP-induced aggregation were reported (but less strong than a pharmacological $\mathrm{P}^{\mathrm{Y}_{12}}$ inhibitor). ${ }^{107-109}$ However, this was not seen in other studies. ${ }^{110,111}$ In a 4-week intervention study with hyperlipidemic subjects, no antiplatelet effects of dried garlic were seen. $^{112}$

\section{Platelet Receptor and Signaling Pathways Affected by Phytochemicals In Vitro or In Vivo}

The current literature on phytochemicals and platelets is quite diverse with most papers using different doses, types of 
Nutrition Phytochemicals and Platelets Tamer et al. $\quad 889$

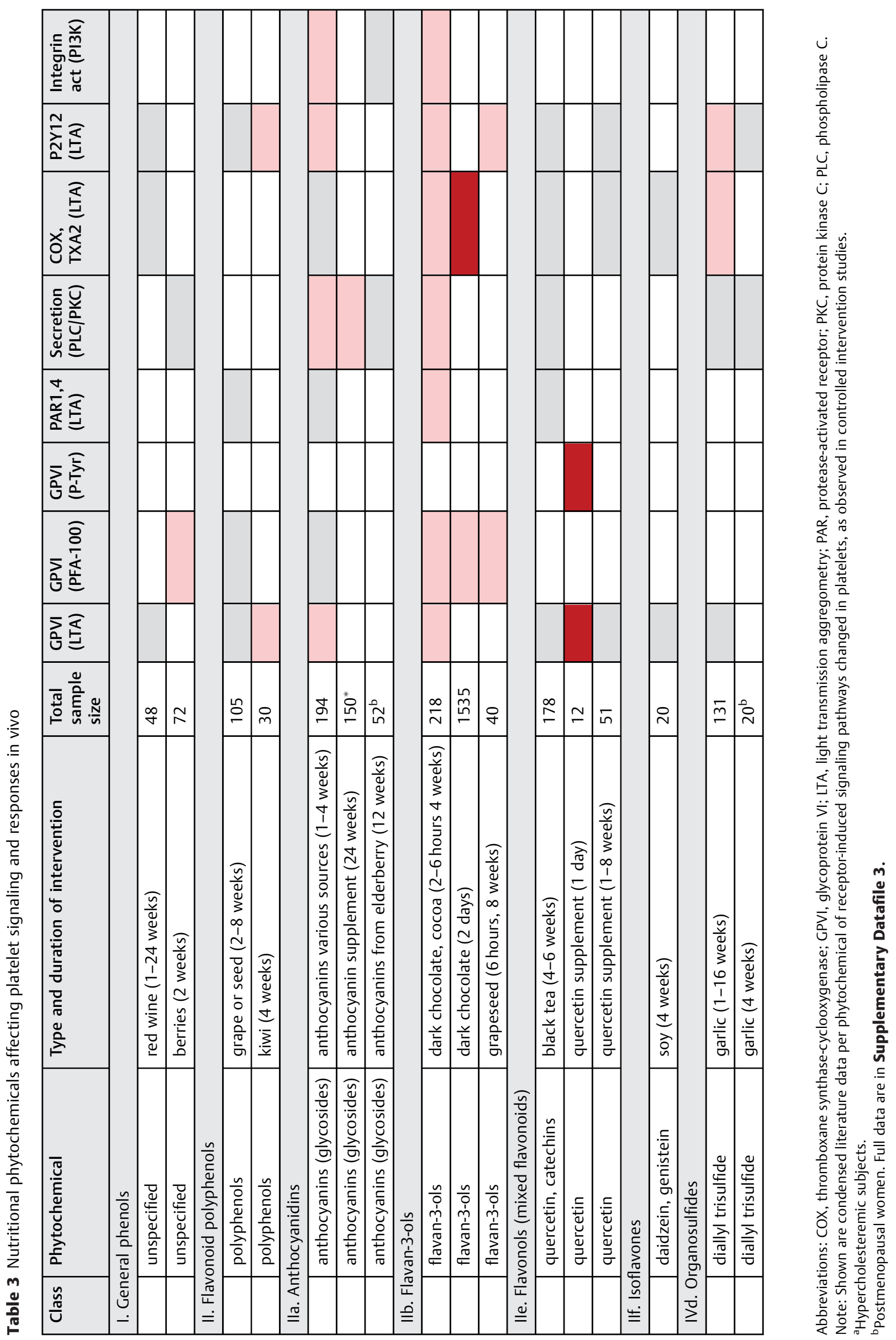


phytochemical preparations tested, intervention schemes, types of functional assays with or without plasma, and receptor and signaling pathways examined. Nevertheless, in agreement with the hit list of - Fig. 3B, several "hot-spot" receptor signaling entities can be identified that are most strongly influenced by the investigated phytochemicals. From in vitro studies (see - Table 2) it appears that the following pathways are preferably affected, although the precise molecular targets are unknown. Note that these listed pathways may partly overlap.

- GPVI collagen receptor signaling via PLCY2, tyrosine kinases Src and Syk. Compounds (phytochemical class) that are interfering include: curcumin (Ia), honokiol (Ib), chlorogenic acid (Ic), resveratrol (Ie), anthocyanidins like delphinidin-3-glucoside (IIa), catechins (IIb), morin (IId), kaempferol and quercetin (IIe), genistein (IIf), and diallyl trisulfide (IVd).

- PAR thrombin receptor activation along with PLC route of $\mathrm{Ca}^{2+}$ mobilization may be less frequently influenced, with most strongly reported effects of caffeic acid (Ic), catechins (IIb), apigenin and morin (IId), kaempferol and quercetin (IIe), and diallyl trisulfide (IVd).

- $T X A_{2}$ receptor and formation via COX. Best reported effects of the COX enforcement pathway are by: curcumin (Ia), caffeic acid (Ic), resveratrol (Ie), apigenin (IId), myricetin and quercetin (IIe), genistein (IIf).

- $P 2 Y_{12}$ receptor and signaling to integrin activation via PI3K and Akt. The main route of autocrine platelet aggregation is mostly suppressed by: curcumin (Ia), silybin (Ib), caffeic and chlorogenic acid (Ic), isorhapontigenin and resveratrol (Ie), delphinidin 3-glucoside (IIa), catechins (IIb), apigenin (IId), kaempferol and quercetin (IIe), and diallyl trisulfide (IVd).

- MAPK isoforms including ERK and p38. Inhibitory compounds include caffeic acid (Ic), resveratrol (Ie), epigallocatechin (IIb), morin (IId), kaempferol (IIe), genistein (IIf).

- Integrin $\alpha_{I I b} \beta_{3}$ activation via PDI. The compound myricetin (IIe).

- Enforced platelet inhibition via cAMP, PKA, cGMP, PDE. Compounds reported are: silybin (Ia), caffeic and chlorogenic acid (Ic), isorhapontigenin (Ie), epigallocatechin (IIb), morin and nobiletin (IId), and quercetin (IIe).

Comparing this to the overall results of in vivo interventions (-Table 3), it appears that only the effects of anthocyanidins (IIa), flavan-3-ols (IIb, cocoa), and the flavonol quercetin (IIe) are recapitulated in terms of these antiplatelet effects, although with lower strength, while organosulfides (IVd, garlic) has a low residual effect as well. Promising, furthermore, is that in vivo in mouse models arterial thrombosis tendency was found to be reduced by anthocyanidins ${ }^{71}$ and by the flavonol kaempferol, ${ }^{63}$ whereas intake of organosulfides attenuated murine atherosclerosis. ${ }^{113}$

\section{Implications for Thrombosis and Hemostasis}

The majority of the reviewed phytochemicals required relatively high doses $\left(10^{-4}-10^{-5} \mathrm{M}\right)$ to be active on platelets in vitro, and these doses may further increase when plasma is present, for instance in case of resveratrol. ${ }^{58}$ This in general explains the relatively small effect sizes on platelets observed in the nutritional intervention studies, in which relatively low doses are ingested. Since nutritional intervention in general appears to be of limited platelet-modulating consequences, specific dietary interventions are not expected to strongly impact the thrombosis risk purely by affecting platelet function. However, direct phytochemical supplementation can have a stronger effect, especially when some of the most active phytochemical types are further improved. The current high dosing is only one drawback for the testing of such compounds for possible therapeutical intervention. Other limitations are the often unclear metabolic absorption of the phytochemicals and their metabolites, ${ }^{114}$ the pharmacokinetic profile in blood and nonplatelet effects, which for the cardiovascular system may be positive or negative. However, as already postulated by others, the acquired knowledge on effects of certain phytochemicals, as platelet-inhibiting compounds, can be employed for the further selection and chemical modification of these in the design of effective antiplatelet drugs. ${ }^{115}$ In other words, those phytochemical compounds with a proven effect on platelets and thrombus formation can trigger new ways for drug discovery. This could develop into new antiplatelet drugs, and also to potentiate the action of current antiplatelet drugs, as several of the phytochemicals seem to have priming effects on platelets. Interestingly, combinations of phytochemicals can have synergistic effects on platelets, ${ }^{64,79}$ which will further enhance the priming.

Of the examined phytochemicals, several appeared to stand out as interesting targets for possible clinical use. Quercetin (class IIe) is interesting, as its supplementation showed promising effects in vivo with a clinically relevant reduction in GPVI-induced platelet aggregation. ${ }^{75,116}$ Moreover, multiple in vitro studies showed antiplatelet effects regarding several signaling pathways. ${ }^{53,64,65,69,105,117,118}$ Also, flavan-3-ols (class IIb) are of interest, as these showed a reduced platelet activation in response to ADP, thrombin, and collagen in vitro. ${ }^{66,119,120}$ In vivo, flavan-3-ols have only been studied in food intervention trials, leaving the possibility that supplementation in purified form has an even stronger effect. Lastly, anthocyanidins are of interest, as they inhibited GPVI, PAR, and P2Y-mediated platelet activation in vitro ${ }^{59,60}$ as well as platelet activation in vivo. ${ }^{98,99}$

Regarding quantitative or qualitative platelet changes and hemostasis (bleeding risk), only few information is available, limited to animal studies. Indications on an increased tail bleeding time were made for animals treated with diallyl trisulfides, ${ }^{121}$ curcumin, ${ }^{40,122}$ epigallocatechin, ${ }^{123}$ nobiletin, ${ }^{124}$ or chlorogenic acid. ${ }^{51}$ Few other papers indicated that phytochemicals can inhibit thrombus formation and platelet function without increased tail bleeding times, i.e., for quercetin, ${ }^{125}$ myricetin, ${ }^{72}$ and delphinidin glucoside. ${ }^{63}$

In conclusion, this overview indicates that many phytochemicals to a smaller or larger extent can influence platelet function, albeit only a few can do so at an affordable and clinically relevant dose. However, only for some 
phytochemicals it is clear how they interfere with platelet signaling pathways or receptors, which makes these interesting candidate pharmaceuticals. Future research will need to focus on: (1) chemical modification of these compounds to obtain better or more specific antiplatelet agents, and (2) optimization of the isolation or synthesis of selected phytochemicals for concentrated supplementation, before use as antiplatelet drugs.

\section{Author Contributions}

F.T., B.M.E.T., M.J.E.K., T.A.M.C., and J.W.M.H. performed research, analyzed data, drafted, and wrote the manuscript.

\section{Funding}

This study was funded by Scientific and Technological Research Council of Turkey.

Conflict of interest

None declared.

\section{References}

1 Piepoli MF, Hoes AW, Agewall S, et al; ESC Scientific Document Group. 2016 European guidelines on cardiovascular disease prevention in clinical practice: The Sixth Joint Task Force of the European Society of Cardiology and Other Societies on Cardiovascular Disease Prevention in Clinical Practice (constituted by representatives of 10 societies and by invited experts) Developed with the special contribution of the European Association for Cardiovascular Prevention \& Rehabilitation (EACPR). Eur Heart J 2016;37(29):2315-2381

2 van der Meijden PEJ, Heemskerk JWM. Platelet biology and functions: new concepts and clinical perspectives. Nat Rev Cardiol 2019;16(03):166-179

3 Versteeg HH, Heemskerk JW, Levi M, Reitsma PH. New fundamentals in hemostasis. Physiol Rev 2013;93(01):327-358

4 Fernández DI, Kuijpers MJE, Heemskerk JWM. Platelet calcium signaling by G-protein coupled and ITAM-linked receptors regulating anoctamin-6 and procoagulant activity. Platelets 2021; 32(07):863-871

5 Swieringa F, Kuijpers MJ, Heemskerk JW, van der Meijden PE. Targeting platelet receptor function in thrombus formation: the risk of bleeding. Blood Rev 2014;28(01):9-21

6 Baaten CCFMJ, Ten Cate H, van der Meijden PEJ, Heemskerk JWM. Platelet populations and priming in hematological diseases. Blood Rev 2017;31(06):389-399

7 Satoh K, Satoh T, Yaoita N, Shimokawa H. Recent advances in the understanding of thrombosis. Arterioscler Thromb Vasc Biol 2019;39(06):e159-e165

8 Mertens E, Markey O, Geleijnse JM, Givens DI, Lovegrove JA. Dietary patterns in relation to cardiovascular disease incidence and risk markers in a middle-aged British male population: data from the Caerphilly prospective study. Nutrients 2017;9(01):75

9 Molyneux RJ, Lee ST, Gardner DR, Panter KE, James LF. Phytochemicals: the good, the bad and the ugly? Phytochemistry 2007;68(22-24):2973-2985

10 U.S. Food and Drug Administration. Health claims: fiber-containing grain products, fruits, and vegetables and cancer. Title 21: Food and Drugs Subpart E 2017; 10176. Accessed January 8, 2017 at: https://www.accessdata.fda.gov/scripts/cdrh/cfdocs/ cfcfr/CFRSearch.cfm?fr=101.76

11 European Food Safety Authority. Scientific opinion on the substantiation of health claims related to various food(s)/food constituent(s) and protection of cells from premature aging, antioxidant activity, antioxidant content and antioxidant properties, and protection of DNA, proteins and lipids from oxidative damage pursuant to Article 13(1) of Regulation (EC) No 1924/20061. EFSA J 2010;8:1489

12 U.S. Food and Drug Administration. Food labeling, subpart D, specific requirements for nutrient content claims, section 101.54. Code of Federal Regulations 2016;21(Part 101):2017

13 Shaw D. Toxicological risks of Chinese herbs. Planta Med 2010;76 (17):2012-2018

14 Manach C, Scalbert A, Morand C, Rémésy C, Jiménez L. Polyphenols: food sources and bioavailability. Am J Clin Nutr 2004;79 (05):727-747

15 Barbieri R, Coppo E, Marchese A, et al. Phytochemicals for human disease: an update on plant-derived compounds antibacterial activity. Microbiol Res 2017;196:44-68

16 Lewandowska H, Kalinowska M, Lewandowski W, Stępkowski TM, Brzóska K. The role of natural polyphenols in cell signaling and cytoprotection against cancer development. J Nutr Biochem 2016;32:1-19

17 Keihanian F, Saeidinia A, Bagheri RK, Johnston TP, Sahebkar A. Curcumin, hemostasis, thrombosis, and coagulation. J Cell Physiol 2018;233(06):4497-4511

18 Rauf A, Patel S, Imran M, et al. Honokiol: an anticancer lignan. Biomed Pharmacother 2018;107:555-562

19 Calado A, Neves PM, Santos T, Ravasco P. The effect of flaxseed in breast cancer: a literature review. Front Nutr 2018;5:4

20 Grassi D, Desideri G, Di Giosia P, et al. Tea, flavonoids, and cardiovascular health: endothelial protection. Am J Clin Nutr 2013;98(6, Suppl):1660S-1666S

21 Ali SS, Ahmad WANW, Budin SB, Zainalabidin S. Implication of dietary phenolic acids on inflammation in cardiovascular disease. Rev Cardiovasc Med 2020;21(02):225-240

22 Anantharaju PG, Gowda PC, Vimalambike MG, Madhunapantula SV. An overview on the role of dietary phenolics for the treatment of cancers. Nutr J 2016;15(01):99

23 Signorelli P, Ghidoni R. Resveratrol as an anticancer nutrient: molecular basis, open questions and promises. J Nutr Biochem 2005;16(08):449-466

24 Ramprasath VR, Jones PJ. Anti-atherogenic effects of resveratrol. Eur J Clin Nutr 2010;64(07):660-668

25 Wang TY, Li Q Bi KS. Bioactive flavonoids in medicinal plants: structure, activity and biological fate. Asian J Pharm Sci 2018;13 (01):12-23

26 Guo H, Ling W. The update of anthocyanins on obesity and type 2 diabetes: experimental evidence and clinical perspectives. Rev Endocr Metab Disord 2015;16(01):1-13

27 The devil in the dark chocolate. Lancet 2007;370:2070

28 Mulvihill EE, Burke AC, Huff MW. Citrus flavonoids as regulators of lipoprotein metabolism and atherosclerosis. Annu Rev Nutr 2016;36:275-299

29 López-Lázaro M. Distribution and biological activities of the flavonoid luteolin. Mini Rev Med Chem 2009;9(01):31-59

30 Boots AW, Li H, Schins RP, et al. The quercetin paradox. Toxicol Appl Pharmacol 2007;222(01):89-96

31 Rangel-Huerta OD, Pastor-Villaescusa B, Aguilera CM, Gil A. A systematic review of the efficacy of bioactive compounds in cardiovascular disease: phenolic compounds. Nutrients 2015;7 (07):5177-5216

32 Ørgaard A, Jensen L. The effects of soy isoflavones on obesity. Exp Biol Med (Maywood) 2008;233(09):1066-1080

33 Eggersdorfer M, Wyss A. Carotenoids in human nutrition and health. Arch Biochem Biophys 2018;652:18-26

34 Katz E, Nisani S, Chamovitz DA. Indole-3-carbinol: a plant hormone combatting cancer. F1000 Res 2018;7:1

35 Butt MS, Sultan MT, Butt MS, Iqbal J. Garlic: nature's protection against physiological threats. Crit Rev Food Sci Nutr 2009;49 (06):538-551 
36 Lissiman E, Bhasale AL, Cohen M. Garlic for the common cold Cochrane Database Syst Rev 2014;11(11):CD006206

37 Köhler J, Teupser D, Elsässer A, Weingärtner O. Plant sterol enriched functional food and atherosclerosis. $\mathrm{Br} \mathrm{J}$ Pharmacol 2017;174(11):1281-1289

38 Mayanglambam A, Dangelmaier CA, Thomas D, Damodar Reddy C, Daniel JL, Kunapuli SP. Curcumin inhibits GPVI-mediated platelet activation by interfering with the kinase activity of Syk and the subsequent activation of PLCgamma2. Platelets 2010;21(03):211-220

39 Shah BH, Nawaz Z, Pertani SA, et al. Inhibitory effect of curcumin, a food spice from turmeric, on platelet-activating factor- and arachidonic acid-mediated platelet aggregation through inhibition of thromboxane formation and $\mathrm{Ca} 2+$ signaling. Biochem Pharmacol 1999;58(07):1167-1172

40 Prakash P, Misra A, Surin WR, et al. Anti-platelet effects of Curcuma oil in experimental models of myocardial ischemiareperfusion and thrombosis. Thromb Res 2011;127(02): 111-118

41 Onselaer MB, Nagy M, Pallini C, et al. Comparison of the GPVI inhibitors losartan and honokiol. Platelets 2020;31(02):187-197

42 Bijak M, Szelenberger R, Dziedzic A, Saluk-Bijak J. Inhibitory effect of flavonolignans on the $\mathrm{P}_{2} \mathrm{Y}_{12}$ pathway in blood platelets. Molecules 2018;23(02):374

43 Bijak M, Szelenberger R, Saluk J, Nowak P. Flavonolignans inhibit ADP induced blood platelets activation and aggregation in whole blood. Int J Biol Macromol 2017;95:682-688

44 Parveen R, Baboota S, Ali J, Ahuja A, Vasudev SS, Ahmad S. Oil based nanocarrier for improved oral delivery of silymarin: in vitro and in vivo studies. Int J Pharm 2011;413(1-2):245-253

45 Olthof MR, Hollman PC, Katan MB. Chlorogenic acid and caffeic acid are absorbed in humans. J Nutr 2001;131(01):66-71

46 Park JB. 5-Caffeoylquinic acid and caffeic acid orally administered suppress P-selectin expression on mouse platelets. J Nutr Biochem 2009;20(10):800-805

47 Ostertag LM, O'Kennedy N, Horgan GW, Kroon PA, Duthie GG, de Roos B. In vitro anti-platelet effects of simple plant-derived phenolic compounds are only found at high, non-physiological concentrations. Mol Nutr Food Res 2011;55(11):1624-1636

48 Nam GS, Park HJ, Nam KS. The antithrombotic effect of caffeic acid is associated with a cAMP-dependent pathway and clot retraction in human platelets. Thromb Res 2020;195:87-94

49 Lee DH, Kim HH, Cho HJ, Bae JS, Yu YB, Park HJ. Antiplatelet effects of caffeic acid due to $\mathrm{Ca}(2+)$ mobilizationinhibition via cAMP-dependent inositol-1, 4, 5-trisphosphate receptor phosphorylation. J Atheroscler Thromb 2014;21(01):23-37

50 Lu Y, Li Q, Liu YY, et al. Inhibitory effect of caffeic acid on ADPinduced thrombus formation and platelet activation involves mitogen-activated protein kinases. Sci Rep 2015;5:13824

51 Fuentes E, Caballero J, Alarcón M, Rojas A, Palomo I. Chlorogenic acid inhibits human platelet activation and thrombus formation. PLoS One 2014;9(03):e90699

52 Ok WJ, Cho HJ, Kim HH, et al. Epigallocatechin-3-gallate has an anti-platelet effect in a cyclic AMP-dependent manner. J Atheroscler Thromb 2012;19(04):337-348

53 Crescente M, Jessen G, Momi S, et al. Interactions of gallic acid, resveratrol, quercetin and aspirin at the platelet cyclooxygenase1 level. Functional and modelling studies. Thromb Haemost 2009;102(02):336-346

54 Lill G, Voit S, Schrör K, Weber AA. Complex effects of different green tea catechins on human platelets. FEBS Lett 2003;546(23):265-270

55 Veach D, Hosking H, Thompson K, Santhakumar AB. Anti-platelet and anti-thrombogenic effects of shikimic acid in sedentary population. Food Funct 2016;7(08):3609-3616

56 Ravishankar D, Albadawi DAI, Chaggar V, et al. Isorhapontigenin, a resveratrol analogue selectively inhibits ADP-stimulated platelet activation. Eur J Pharmacol 2019;862:172627
57 Wang Z, Huang Y, Zou J, Cao K, Xu Y, Wu JM. Effects of red wine and wine polyphenol resveratrol on platelet aggregation in vivo and in vitro. Int J Mol Med 2002;9(01):77-79

58 Kirk RI, Deitch JA, Wu JM, Lerea KM. Resveratrol decreases early signaling events in washed platelets but has little effect on platelet in whole blood. Blood Cells Mol Dis 2000;26(02): $144-150$

59 Rechner AR, Kroner C. Anthocyanins and colonic metabolites of dietary polyphenols inhibit platelet function. Thromb Res 2005; 116(04):327-334

60 Krga I, Vidovic N, Milenkovic D, et al. Effects of anthocyanins and their gut metabolites on adenosine diphosphate-induced platelet activation and their aggregation with monocytes and neutrophils. Arch Biochem Biophys 2018;645:34-41

61 Yao Y, Chen Y, Adili R, et al. Plant-based food cyanidin-3-glucoside modulates human platelet glycoprotein VI signaling and inhibits platelet activation and thrombus formation. J Nutr 2017; 147(10):1917-1925

62 Czank C, Cassidy A, Zhang Q et al. Human metabolism and elimination of the anthocyanin, cyanidin-3-glucoside: a (13)Ctracer study. Am J Clin Nutr 2013;97(05):995-1003

63 Yang Y, Shi Z, Reheman A, et al. Plant food delphinidin-3glucoside significantly inhibits platelet activation and thrombosis: novel protective roles against cardiovascular diseases. PLoS One 2012;7(05):e37323

64 Pignatelli P, Pulcinelli FM, Celestini A, et al. The flavonoids quercetin and catechin synergistically inhibit platelet function by antagonizing the intracellular production of hydrogen peroxide. Am J Clin Nutr 2000;72(05):1150-1155

65 Wright B, Moraes LA, Kemp CF, et al. A structural basis for the inhibition of collagen-stimulated platelet function by quercetin and structurally related flavonoids. Br J Pharmacol 2010;159 (06):1312-1325

66 Kang WS, Chung KH, Chung JH, et al. Antiplatelet activity of green tea catechins is mediated by inhibition of cytoplasmic calcium increase. J Cardiovasc Pharmacol 2001;38(06):875-884

67 Iida Y, Doi T, Matsushima-Nishiwaki R, et al. (-)-Epigallocatechin gallate selectively inhibits adenosine diphosphate-stimulated human platelet activation: suppression of heat shock protein 27 phosphorylation via p38 mitogen-activated protein kinase. Mol Med Rep 2014;10(03):1383-1388

68 Guerrero JA, Navarro-Nuñez L, Lozano ML, et al. Flavonoids inhibit the platelet $\operatorname{TxA}(2)$ signalling pathway and antagonize $\operatorname{TxA}(2)$ receptors (TP) in platelets and smooth muscle cells. Br J Clin Pharmacol 2007;64(02):133-144

69 Navarro-Núñez L, Rivera J, Guerrero JA, Martínez C, Vicente V, Lozano ML. Differential effects of quercetin, apigenin and genistein on signalling pathways of protease-activated receptors PAR (1) and PAR(4) in platelets. Br J Pharmacol 2009;158(06): $1548-1556$

70 Nam GS, Lee KS, Nam KS. Morin hydrate inhibits platelet activation and clot retraction by regulating integrin $\alpha_{\mathrm{IIb}} \beta_{3}, \mathrm{TXA}_{2}$, and cAMP levels. Eur J Pharmacol 2019;865:172734

71 Choi JH, Park SE, Kim SJ, Kim S. Kaempferol inhibits thrombosis and platelet activation. Biochimie 2015;115:177-186

72 Gaspar RS, da Silva SA, Stapleton J, et al. Myricetin, the main flavonoid in Syzygium cumini leaf, is a novel inhibitor of platelet thiol isomerases PDI and ERp5. Front Pharmacol 2020;10:1678

73 Dang Y, Lin G, Xie Y, et al. Quantitative determination of myricetin in rat plasma by ultra performance liquid chromatography tandem mass spectrometry and its absolute bioavailability. Drug Res (Stuttg) 2014;64(10):516-522

74 Lescano CH, Freitas de Lima F, Mendes-Silvério CB, et al. Effect of polyphenols from Campomanesia adamantium on platelet aggregation and inhibition of cyclooxygenases: molecular docking and in vitro analysis. Front Pharmacol 2018;9:617

75 Hubbard GP, Wolffram S, Lovegrove JA, Gibbins JM. Ingestion of quercetin inhibits platelet aggregation and essential 
components of the collagen-stimulated platelet activation pathway in humans. J Thromb Haemost 2004;2(12):2138-2145

76 Pignatelli P, Di Santo S, Buchetti B, Sanguigni V, Brunelli A, Violi F. Polyphenols enhance platelet nitric oxide by inhibiting protein kinase C-dependent NADPH oxidase activation: effect on platelet recruitment. FASEB J 2006;20(08):1082-1089

77 Beretz A, Stierle A, Anton R, Cazenave JP. Role of cyclic AMP in the inhibition of human platelet aggregation by quercetin, a flavonoid that potentiates the effect of prostacyclin. Biochem Pharmacol 1982;31(22):3597-3600

78 Lanza F, Beretz A, Stierlé A, Corre G, Cazenave JP. Cyclic nucleotide phosphodiesterase inhibitors prevent aggregation of human platelets by raising cyclic AMP and reducing cytoplasmic free calcium mobilization. Thromb Res 1987;45(05):477-484

79 Shanmuganayagam D, Beahm MR, Osman HE, Krueger CG, Reed JD, Folts JD. Grape seed and grape skin extracts elicit a greater antiplatelet effect when used in combination than when used individually in dogs and humans. J Nutr 2002;132(12): 3592-3598

80 Gottstein N, Ewins BA, Eccleston C, et al. Effect of genistein and daidzein on platelet aggregation and monocyte and endothelial function. Br J Nutr 2003;89(05):607-616

81 Kondo K, Suzuki Y, Ikeda Y, Umemura K. Genistein, an isoflavone included in soy, inhibits thrombotic vessel occlusion in the mouse femoral artery and in vitro platelet aggregation. Eur J Pharmacol 2002;455(01):53-57

82 Kansra SV, Reddy MA, Weng YI, Shukla SD. Activation of mitogen activated protein kinase in human platelets by genistein. Pharmacol Res 1999;39(01):21-31

83 Ozaki Y, Yatomi Y, Jinnai Y, Kume S. Effects of genistein, a tyrosine kinase inhibitor, on platelet functions. Genistein attenuates thrombin-induced $\mathrm{Ca} 2+$ mobilization in human platelets by affecting polyphosphoinositide turnover. Biochem Pharmacol 1993;46(03):395-403

84 Nakashima S, Koike T, Nozawa Y. Genistein, a protein tyrosine kinase inhibitor, inhibits thromboxane A2-mediated human platelet responses. Mol Pharmacol 1991;39(04):475-480

$85 \mathrm{Kim} \mathrm{K}$, Lim KM, Kim CW, et al. Black soybean extract can attenuate thrombosis through inhibition of collagen-induced platelet activation. J Nutr Biochem 2011;22(10):964-970

86 Hosono T, Sato A, Nakaguchi N, Ozaki-Masuzawa Y, Seki T. Diallyl trisulfide inhibits platelet aggregation through the modification of sulfhydryl groups. J Agric Food Chem 2020;68(06):1571-1578

87 Chan KC, Hsu CC, Yin MC. Protective effect of three diallyl sulphides against glucose-induced erythrocyte and platelet oxidation, and ADP-induced platelet aggregation. Thromb Res 2002; 108(5-6):317-322

88 Qi R, Liao F, Inoue K, Yatomi Y, Sato K, Ozaki Y. Inhibition by diallyl trisulfide, a garlic component, of intracellular $\mathrm{Ca}(2+)$ mobilization without affecting inositol-1,4, 5-trisphosphate (IP(3)) formation in activated platelets. Biochem Pharmacol 2000;60(10): 1475-1483

89 Badol P, David-Dufilho M, Auger J, Whiteheart SW, Rendu F. Thiosulfinates modulate platelet activation by reaction with surface free sulfhydryls and internal thiol-containing proteins. Platelets 2007;18(07):481-490

90 Thushara RM, Hemshekhar M, Santhosh MS, et al. Crocin, a dietary additive protects platelets from oxidative stress-induced apoptosis and inhibits platelet aggregation. Mol Cell Biochem 2013;373(1-2):73-83

91 Keen CL, Holt RR, Polagruto JA, Wang JF, Schmitz HH. Cocoa flavanols and cardiovascular health. Phytochem Rev 2002; $1: 231-240$

92 Pellegrini N, Pareti FI, Stabile F, Brusamolino A, Simonetti P. Effects of moderate consumption of red wine on platelet aggregation and haemostatic variables in healthy volunteers. Eur J Clin Nutr 1996;50(04):209-213
93 Kikura M, Levy JH, Safon RA, Lee MK, Szlam F. The influence of red wine or white wine intake on platelet function and viscoelastic property of blood in volunteers. Platelets 2004;15(01): 37-41

94 Erlund I, Koli R, Alfthan G, et al. Favorable effects of berry consumption on platelet function, blood pressure, and HDL cholesterol. Am J Clin Nutr 2008;87(02):323-331

95 Ras RT, Zock PL, Zebregs YE, Johnston NR, Webb DJ, Draijer R. Effect of polyphenol-rich grape seed extract on ambulatory blood pressure in subjects with pre- and stage I hypertension. Br J Nutr 2013;110(12):2234-2241

96 Duttaroy AK, Jørgensen A. Effects of kiwi fruit consumption on platelet aggregation and plasma lipids in healthy human volunteers. Platelets 2004;15(05):287-292

97 Keevil JG, Osman HE, Reed JD, Folts JD. Grape juice, but not orange juice or grapefruit juice, inhibits human platelet aggregation. J Nutr 2000;130(01):53-56

98 Thompson K, Hosking H, Pederick W, Singh I, Santhakumar AB. The effect of anthocyanin supplementation in modulating platelet function in sedentary population: a randomised, doubleblind, placebo-controlled, cross-over trial. Br J Nutr 2017;118 (05):368-374

99 Thompson K, Pederick W, Singh I, Santhakumar AB. Anthocyanin supplementation in alleviating thrombogenesis in overweight and obese population: a randomized, double-blind, placebocontrolled study. J Funct Foods 2017;32:131-138

100 Song F, Zhu Y, Shi Z, et al. Plant food anthocyanins inhibit platelet granule secretion in hypercholesterolaemia: Involving the signalling pathway of PI3K-Akt. Thromb Haemost 2014;112(05): 981-991

101 Ostertag LM, Kroon PA, Wood S, et al. Flavan-3-ol-enriched dark chocolate and white chocolate improve acute measures of platelet function in a gender-specific way-a randomized-controlled human intervention trial. Mol Nutr Food Res 2013;57 (02):191-202

102 Bordeaux B, Yanek LR, Moy TF, et al. Casual chocolate consumption and inhibition of platelet function. Prev Cardiol 2007;10 (04):175-180

103 Polagruto JA, Gross HB, Kamangar F, et al. Platelet reactivity in male smokers following the acute consumption of a flavanol-rich grapeseed extract. J Med Food 2007;10(04):725-730

104 Conquer JA, Maiani G, Azzini E, Raguzzini A, Holub BJ. Supplementation with quercetin markedly increases plasma quercetin concentration without effect on selected risk factors for heart disease in healthy subjects. J Nutr 1998;128(03):593-597

105 Janssen K, Mensink RP, Cox FJ, et al. Effects of the flavonoids quercetin and apigenin on hemostasis in healthy volunteers: results from an in vitro and a dietary supplement study. Am J Clin Nutr 1998;67(02):255-262

106 Gooderham MH, Adlercreutz H, Ojala ST, Wähälä K, Holub BJ. A soy protein isolate rich in genistein and daidzein and its effects on plasma isoflavone concentrations, platelet aggregation, blood lipids and fatty acid composition of plasma phospholipid in normal men. J Nutr 1996;126(08):2000-2006

107 Fakhar H, Hashemi Tayer A. Effect of the garlic pill in comparison with plavix on platelet aggregation and bleeding time. Iran J Ped Hematol Oncol 2012;2(04):146-152

108 Legnani C, Frascaro M, Guazzaloca G, Ludovici S, Cesarano G, Coccheri S. Effects of a dried garlic preparation on fibrinolysis and platelet aggregation in healthy subjects. Arzneimittelforschung 1993;43(02):119-122

109 Rahman K, Lowe GM, Smith S. Aged garlic extract inhibits human platelet aggregation by altering intracellular signaling and platelet shape change. J Nutr 2016;146(02):410S-415S

110 Wojcikowski K, Myers S, Brooks L. Effects of garlic oil on platelet aggregation: a double-blind placebo-controlled crossover study. Platelets 2007;18(01):29-34 
111 Morris J, Burke V, Mori TA, Vandongen R, Beilin LJ. Effects of garlic extract on platelet aggregation: a randomized placebo-controlled double-blind study. Clin Exp Pharmacol Physiol 1995; 22(6-7):414-417

112 Harenberg J, Giese C, Zimmermann R. Effect of dried garlic on blood coagulation, fibrinolysis, platelet aggregation and serum cholesterol levels in patients with hyperlipoproteinemia. Atherosclerosis 1988;74(03):247-249

113 Morihara N, Hino A, Yamaguchi T, Suzuki J. Aged garlic extract suppresses the development of atherosclerosis in apolipoprotein E-knockout mice. J Nutr 2016;146(02):460S-463S

114 Clifford MN, van der Hooft JJ, Crozier A. Human studies on the absorption, distribution, metabolism, and excretion of tea polyphenols. Am J Clin Nutr 2013;98(6, Suppl):1619S-1630S

115 Wright B, Spencer JP, Lovegrove JA, Gibbins JM. Insights into dietary flavonoids as molecular templates for the design of antiplatelet drugs. Cardiovasc Res 2013;97(01):13-22

116 Hubbard GP, Wolffram S, de Vos R, Bovy A, Gibbins JM, Lovegrove JA. Ingestion of onion soup high in quercetin inhibits platelet aggregation and essential components of the collagen-stimulated platelet activation pathway in man: a pilot study. $\mathrm{Br} \mathrm{J}$ Nutr 2006;96(03):482-488

117 Bucki R, Pastore JJ, Giraud F, Sulpice JC, Janmey PA. Flavonoid inhibition of platelet procoagulant activity and phosphoinositide synthesis. J Thromb Haemost 2003;1(08):1820-1828

118 Guglielmone HA, Agnese AM, Núñez Montoya SC, Cabrera JL. Inhibitory effects of sulphated flavonoids isolated from Flaveria bidentis on platelet aggregation. Thromb Res 2005;115(06): 495-502

119 Bijak M, Sut A, Kosiorek A, Saluk-Bijak J, Golanski J. Dual anticoagulant/antiplatelet activity of polyphenolic grape seeds extract. Nutrients 2019;11(01):93

120 Olas B, Wachowicz B, Stochmal A, Oleszek W. The polyphenolrich extract from grape seeds inhibits platelet signaling pathways triggered by both proteolytic and non-proteolytic agonists. Platelets 2012;23(04):282-289

121 Chan KC, Yin MC, Chao WJ. Effect of diallyl trisulfide-rich garlic oil on blood coagulation and plasma activity of anticoagulation factors in rats. Food Chem Toxicol 2007;45(03):502-507

$122 \mathrm{Li}$ W, Ma Y, Zhang C, et al. Tetrahydrocurcumin downregulates MAPKs/cPLA2 signaling and attenuates platelet thromboxane $\mathrm{A}_{2}$ generation, granule secretion, and thrombus growth. Thromb Haemost 2021. Doi: 10.1055/s-0041-1735192

123 Chen XQ, Wang XB, Guan RF, et al. Blood anticoagulation and antiplatelet activity of green tea (-)-epigallocatechin (EGC) in mice. Food Funct 2013;4(10):1521-1525

124 Vaiyapuri S, Roweth H, Ali MS, et al. Pharmacological actions of nobiletin in the modulation of platelet function. Br J Pharmacol 2015;172(16):4133-4145

125 Oh TW, Do HJ, Jeon JH, Kim K. Quercitrin inhibits platelet activation in arterial thrombosis. Phytomedicine 2021;80:153363

126 Frank J, Fukagawa NK, Bilia AR, et al. Terms and nomenclature used for plant-derived components in nutrition and related research: efforts toward harmonization. Nutr Rev 2020;78(06):451-458 